University of Nebraska - Lincoln

DigitalCommons@University of Nebraska - Lincoln

Hendrik J. Viljoen Publications

Chemical and Biomolecular Research Papers --

Faculty Authors Series

2-1998

\title{
A study of piezoelectric orthorhombic $\mathrm{Ta}_{2} \mathrm{O}_{5}$
}

B. R. Jooste

University of Nebraska - Lincoln

Hendrik J. Viljoen

University of Nebraska - Lincoln, hviljoen1@unl.edu

Follow this and additional works at: https://digitalcommons.unl.edu/cbmeviljoen

Part of the Chemical Engineering Commons

Jooste, B. R. and Viljoen, Hendrik J., "A study of piezoelectric orthorhombic Ta2O5" (1998). Hendrik J.

Viljoen Publications. 14.

https://digitalcommons.unl.edu/cbmeviljoen/14

This Article is brought to you for free and open access by the Chemical and Biomolecular Research Papers -- Faculty Authors Series at DigitalCommons@University of Nebraska - Lincoln. It has been accepted for inclusion in Hendrik J. Viljoen Publications by an authorized administrator of DigitalCommons@University of Nebraska - Lincoln. 


\title{
A study of piezoelectric orthorhombic $\mathrm{Ta}_{2} \mathrm{O}_{5}$
}

\author{
B. R. Jooste and H.J. Viljoen \\ Department of Chemical Engineering, University of Nebraska-Lincoln, Lincoln, Nebraska 68588-0126
}

(Received 12 June 1996; accepted 7 April 1997)

In 1985 it was first reported that monoclinic $\mathrm{Ta}_{2} \mathrm{O}_{5}$ has piezoelectric properties comparable to $\mathrm{ZnO}$. In this work we report on the deposition, characterization, and qualitative assessment of the piezoelectric behavior of orthorhombic $\mathrm{Ta}_{2} \mathrm{O}_{5}$. Reactive magnetron sputtering was used to deposit thin films of $\mathrm{Ta}_{2} \mathrm{O}_{5}$ onto substrates of $316 \mathrm{~L}$ stainless steel. Without substrate heating the crystallinity was poor. A rapid thermal anneal improved the crystallinity. The orthorhombic phase was dominantly present on all substrates. The piezoelectric property was qualitatively assessed, including a high temperature test at $650{ }^{\circ} \mathrm{C}$.

\section{INTRODUCTION}

The polymorphism of $\mathrm{Ta}_{2} \mathrm{O}_{5}$ has been extensively studied and there is general agreement that a low temperature form $\beta-\mathrm{Ta}_{2} \mathrm{O}_{5}$ and a high temperature form $\alpha-\mathrm{Ta}_{2} \mathrm{O}_{5}$ exist. Jehn and $\mathrm{Olzi}^{1}$ proposed a phase diagram for the $\mathrm{Ta}-\mathrm{O}_{2}$ system in the temperature range $1100-2500{ }^{\circ} \mathrm{C}$. It was observed that the transformation of the $\beta$ phase into the $\alpha$ phase begins at about $1360{ }^{\circ} \mathrm{C}$, but the $\beta$ form exists metastably above this temperature until the melting point of the $\beta$ phase is reached at $1785{ }^{\circ} \mathrm{C} .^{2}$

The thermal stability of $\mathrm{Ta}_{2} \mathrm{O}_{5}$ makes it an attractive material for high temperature applications. However, the formation of suboxides at elevated temperatures could be of concern. Boiko et al. ${ }^{3}$ studied the interaction between $\mathrm{Ta}$ and $\mathrm{Ta}_{2} \mathrm{O}_{5}$. Films were vacuum annealed at $337{ }^{\circ} \mathrm{C}$ or $437^{\circ} \mathrm{C}$ and leakage currents were compared with those of similar films annealed in air (presence of moisture provides proton source); no noticeable differences were measured. Oxygen depletion occurs near the interface, but TEM micrographs revealed that the oxygen diffuses along grain boundaries extending from surface dislocations into the Ta. This process causes the appearance of "thinning" regions in the film with finely distributed islands of a separate metal phase. The coexistence of metal and oxide phases instead of a suboxide phase is consistent with the work reported by Dubrovskaya et al. ${ }^{4}$ and Raisman and Holzberg. ${ }^{5}$ Dubrovskaya et al. ${ }^{4}$ found that the $\mathrm{Ta}-\mathrm{O}$ system is of a simple eutectic variety and only two phases exist over the entire composition interval: $\mathrm{Ta}$ and $\mathrm{Ta}_{2} \mathrm{O}_{5}$.

Recently, $\mathrm{Ta}_{2} \mathrm{O}_{5}$ has been investigated because of its high-dielectric constant for use in high-density dynamic random access memory (DRAM) devices. Several studies were reported on the effect of substrates, thermal annealing, and deposition conditions on the leakage current of $\mathrm{Ta}_{2} \mathrm{O}_{5}$ films. In contrast, very little has been published on the piezoelectric properties of $\mathrm{Ta}_{2} \mathrm{O}_{5}$. The first report on the piezoelectric properties of $\mathrm{Ta}_{2} \mathrm{O}_{5}$ was presented by Nakagawa and $\mathrm{Gomi}^{6}$ who deposited monoclinic $\beta-\mathrm{Ta}_{2} \mathrm{O}_{5}$ by reactive sputtering of tantalum in an $\mathrm{Ar}-\mathrm{O}_{2}$ atmosphere with a substrate temperature of $450{ }^{\circ} \mathrm{C}$ or higher. Nakagawa and $\mathrm{Okada}^{7}$ determined the piezoelectric and elastic properties of monoclinic $\beta-\mathrm{Ta}_{2} \mathrm{O}_{5}$ by measuring resonance and antiresonance frequencies across the film. Maeda et al. ${ }^{8}$ described an automated system to make these impedance measurements, and their results were in agreement with the experimental observations of earlier investigators ${ }^{6}$ who found that the electromechanical coupling of $\mathrm{Ta}_{2} \mathrm{O}_{5}$ is comparable to that of $\mathrm{ZnO}$ (002).

No literature was found on the piezoelectric properties of $\mathrm{Ta}_{2} \mathrm{O}_{5}$ at conditions above room temperature. The small volume of data on $\mathrm{Ta}_{2} \mathrm{O}_{5}$ studies for piezoelectric applications indicates that this is not a system that has been intensively studied. Considerably more work was done on temperature effects of ferroelectrics. The motivation for that research stems from a need to compensate for temperature effects, ${ }^{9,10}$ to increase the Curie temperature for measurements at higher temperatures, ${ }^{11,12}$ and to quantify the elastic and electrical properties of composites which may undergo phase transformations. ${ }^{13}$ Other piezoelectric materials which are possible candidates for high-temperature applications include $\alpha$-quartz. However, this material transforms to $\beta$-quartz at approximately $574{ }^{\circ} \mathrm{C}$ and this transformation also involves a significant volume change which often leads to cracking. Zinc oxide is only thermally stable to a temperature of $700{ }^{\circ} \mathrm{C} .{ }^{14}$ Lithium niobate has a Curie temperature of $1210{ }^{\circ} \mathrm{C},{ }^{15}$ but at temperatures above $300{ }^{\circ} \mathrm{C}$ the piezoelectric sensing ability of lithium niobate starts to decrease with further increases in temperature until the sensing ability is lost at the Curie temperature. ${ }^{15}$

Besides the form of $\mathrm{Ta}_{2} \mathrm{O}_{5}$ investigated by Nakagawa and Gomi, ${ }^{6}$ there is also a low temperature form $\left(\beta-\mathrm{Ta}_{2} \mathrm{O}_{5}\right)$ with an orthorhombic crystal structure. ${ }^{16}$ 
No report was found in literature on the piezoelectric behavior of this phase. In this study we report on the piezoelectric behavior of orthorhombic $\beta-\mathrm{Ta}_{2} \mathrm{O}_{5}$. Reactively sputter deposited orthorhombic $\beta-\mathrm{Ta}_{2} \mathrm{O}_{5}$ thin films were investigated for their piezoelectric sensing ability that could potentially be used to detect vibrations in structures over a wide range of temperatures and vibration frequencies. The effect of annealing on the crystallinity and piezoelectric properties of the deposited $\mathrm{Ta}_{2} \mathrm{O}_{5}$ film is also reported.

Amorphous $\mathrm{Ta}_{2} \mathrm{O}_{5}$ films are exclusively formed on substrates which are not externally heated and only crystallize upon annealing above $600{ }^{\circ} \mathrm{C}$ as orthorhombic $\beta-\mathrm{Ta}_{2} \mathrm{O}_{5} \cdot{ }^{17}$ Although amorphous films cannot exhibit piezoelectric properties, signals were obtained from asdeposited films. X-ray results of these films do not show any discernible peaks and these films would usually be considered amorphous. This result can be attributed to microcrystallinity in the as-deposited films. Shimizu et al. ${ }^{18}$ used microdiffraction to obtain insight into the structure of $\mathrm{Ta}_{2} \mathrm{O}_{5}$ films considered "amorphous" by conventional XRD techniques. Microcrystalline regions of $\beta-\mathrm{Ta}_{2} \mathrm{O}_{5}$ were found, which are only a few nanometers in size.

It is accepted that post-deposition annealing of $\mathrm{Ta}_{2} \mathrm{O}_{5}$ films is necessary to restore or improve the crystallinity of the film. ${ }^{18-21}$ Pignolet et al. ${ }^{19}$ used rapid thermal annealing (RTA) to improve the dielectric permittivity. Several authors proposed a two-step annealing process. Advantages include a reduction of the contamination level and an improvement of stoichiometry, ${ }^{18}$ a decrease in the leakage current and defects of films which are used as storage devices, ${ }^{20}$ and lateral growth of crystallites. ${ }^{21}$ For example, Shimizu et al. ${ }^{18}$ annealed films in an ozone atmosphere under UV irradiation followed by a second annealing step in dry $\mathrm{O}_{2}$ at $800{ }^{\circ} \mathrm{C}$.

Greatly increased piezoelectric signals were measured with our sputter-deposited $\mathrm{Ta}_{2} \mathrm{O}_{5}$ films after rapid thermal annealing at temperatures of $700{ }^{\circ} \mathrm{C}$ and higher.

\section{EXPERIMENTAL METHODS}

\section{A. Reactive dc magnetron sputtering}

A glass bell-jar type dc-magnetron sputtering system (KJL EJ1800) was used to deposit thin $\mathrm{Ta}_{2} \mathrm{O}_{5}$ films onto polished stainless steel substrates by means of reactive sputtering of tantalum. Argon was used as carrier gas and oxygen was used as the reactive gas to oxidize the sputtered tantalum. The sputtering chamber was evacuated to a base pressure of $2.7 \mathrm{mPa}$ before the argon and oxygen (10:1 volumetric ratio) were introduced into the chamber. An MKS volumetric gas flowrate controller was used to control the volumetric ratio and flowrates of argon and oxygen. A turbo pump backed by a mechanical roughing pump was used during the entire deposition period to ensure a sputtering pressure of $0.8 \mathrm{~Pa}$. A tantalum target $(99.99 \%$ pure, $5 \mathrm{~cm}$ in diameter, $0.635 \mathrm{~cm}$ thick) was used. The sputtering rate was controlled by controlling the sputtering current at a fixed value $(40 \mathrm{~mA})$. A summary of the sputtering conditions which were used is listed in Table I.

The substrates were polished 316 stainless steel beams with the following dimensions:

Free length: $112 \mathrm{~mm}$

Width: $14.5 \mathrm{~mm}$

Thickness: $0.89 \mathrm{~mm}$

\section{B. Rapid thermal annealing of $\mathrm{Ta}_{2} \mathrm{O}_{5}$ films}

Pignolet et al. ${ }^{19}$ did rapid thermal annealing (RTA) studies of $\mathrm{Ta}_{2} \mathrm{O}_{5}$ films. Films were placed in the furnace for $60 \mathrm{~s}$ after which the furnace was switched off and samples were left there to cool down. In our studies, the samples were placed in a pulsed current, resistively heated furnace (which was preheated to 700,800 , and $900{ }^{\circ} \mathrm{C}$, respectively) for a period of $60 \mathrm{~s}$ and removed to cool down in the atmosphere. The experimental setup for the annealing is shown in Fig. 1.

TABLE I. Reactive dc magnetron sputtering deposition conditions for $\mathrm{Ta}_{2} \mathrm{O}_{5}$ film deposition.

\begin{tabular}{ll}
\hline \hline Carrier gas & $\mathrm{Ar}$ \\
Reactant gas & $\mathrm{O}_{2}$ \\
$\mathrm{O}_{2}$ : Ar volumetric flow ratio & $1: 10$ \\
Total sputtering chamber pressure & $0.8 \mathrm{~Pa}$ \\
Target material & $\mathrm{Ta}(99.99 \%$ pure) \\
Substrate heating & No intentional heating \\
Substrate height above target & $85 \mathrm{~mm}$ \\
Plasma current (controlled) & $40 \mathrm{~mA}$ \\
Deposition time & $3 \mathrm{~h}$ \\
\hline \hline
\end{tabular}

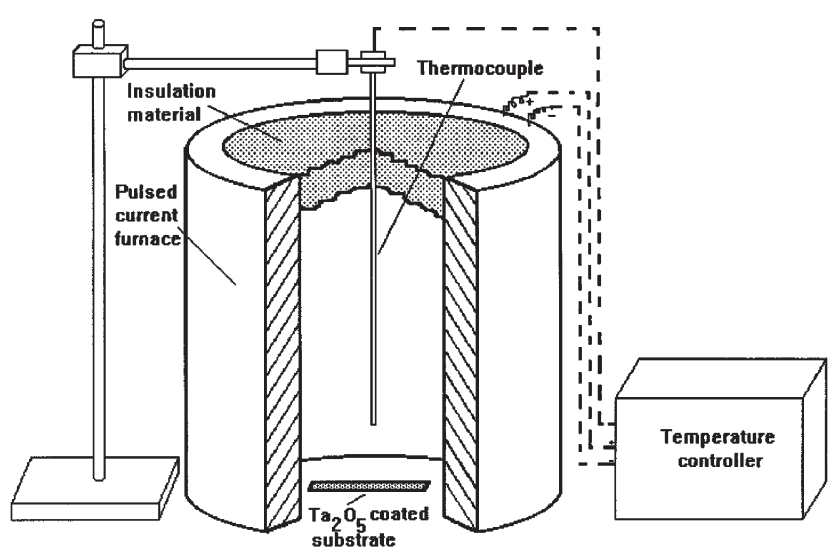

FIG. 1. Schematic of the experimental setup for $\mathrm{Ta}_{2} \mathrm{O}_{5}$ film thermal annealing. 


\section{RESULTS}

\section{A. Film adherence}

After the sputter deposition was completed, the films were inspected with an optical microscope for macrocracks and spalling. The $\mathrm{Ta}_{2} \mathrm{O}_{5}$ films showed excellent adherence to the stainless steel substrate and no sign of film spalling was observed. The films also appeared very uniform and smooth, and no cracks could be observed.

After the RTA treatment was completed, the films were inspected once again. The annealed films still showed very good adherence with no signs of spalling. Also no cracks could be observed in these films.

\section{B. $\mathrm{Ta}_{2} \mathrm{O}_{5}$ film characterization}

$\mathrm{X}$-ray diffraction was used to determine the crystallinity and orientation of the as-deposited (unannealed) and annealed $\mathrm{Ta}_{2} \mathrm{O}_{5}$ films.

The XRD spectrum for unannealed $\mathrm{Ta}_{2} \mathrm{O}_{5}$ films sputter deposited onto stainless steel shown an amorphous hump in the region $22^{\circ} \leqslant 2 \theta \leqslant 33^{\circ}$ (see Fig. 2). The other diffraction peaks at $2 \theta=43.5^{\circ}$ and $44.6^{\circ}$ can be attributed to the stainless steel substrate. The XRD spectrum of the film that was annealed at $700{ }^{\circ} \mathrm{C}$ shows that the film is still amorphous (see Fig. 3).

The $\mathrm{Ta}_{2} \mathrm{O}_{5}$ film annealed at $800{ }^{\circ} \mathrm{C}$ is polycrystalline and the XRD spectrum of the film shows three distinct diffraction peaks that can be attributed to orthorhombic $\beta-\mathrm{Ta}_{2} \mathrm{O}_{5}$ (see Fig. 4). The diffraction peaks at $2 \theta=22.9^{\circ}, 28.3^{\circ}$, and $36.75^{\circ}$ correspond to the $\left(\begin{array}{ll}0 & 0\end{array}\right)$, (1110), and (1111) crystal planes of orthorhombic $\mathrm{Ta}_{2} \mathrm{O}_{5}$, respectively. The $\mathrm{Ta}_{2} \mathrm{O}_{5}$ film annealed at $900{ }^{\circ} \mathrm{C}$ exhibits the same three crystal planes as the film an-

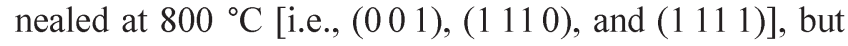

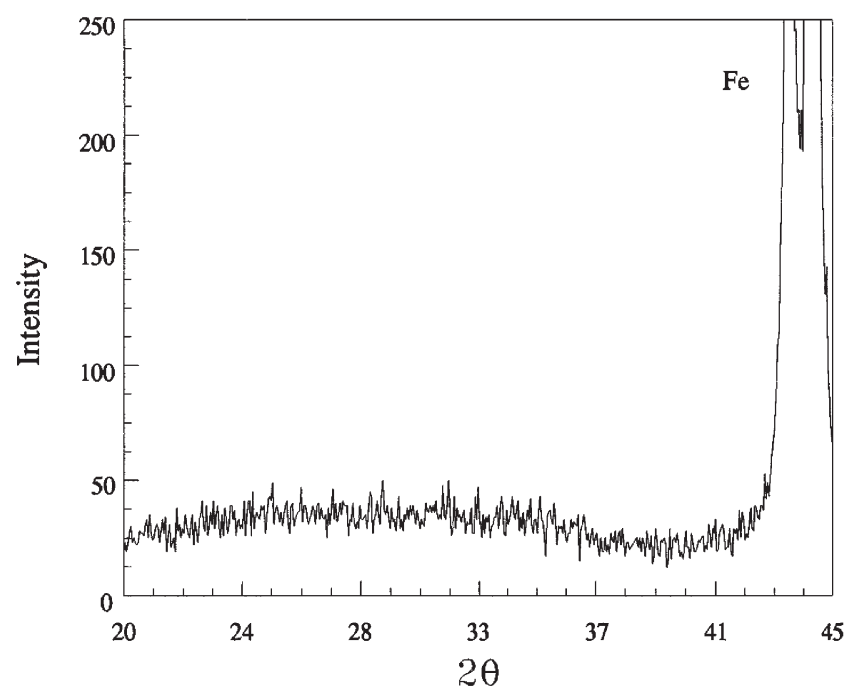

FIG. 2. XRD diagram of unannealed $\mathrm{Ta}_{2} \mathrm{O}_{5}$ film.

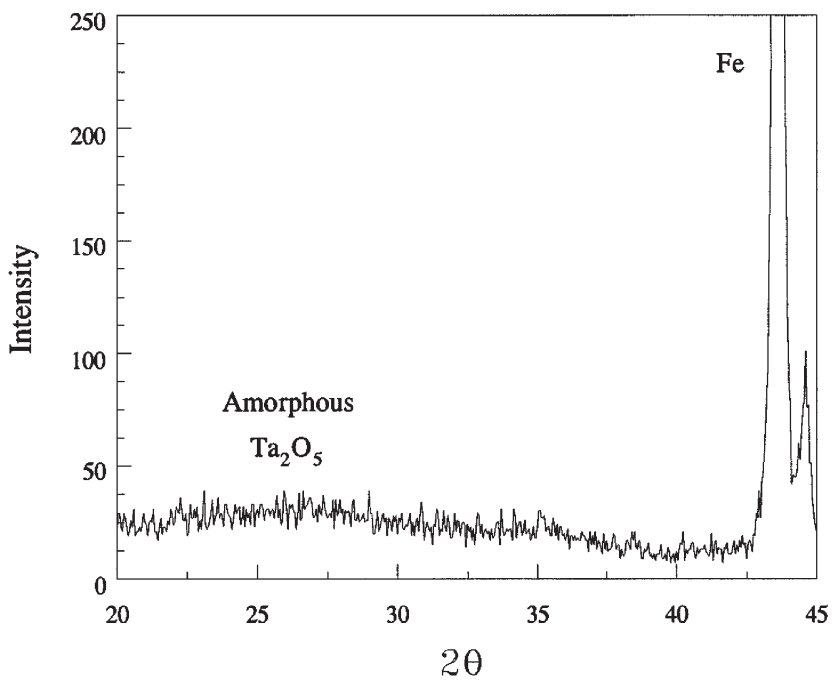

FIG. 3. XRD diagram of $\mathrm{Ta}_{2} \mathrm{O}_{5}$ film annealed at $700{ }^{\circ} \mathrm{C}$ for $60 \mathrm{~s}$.

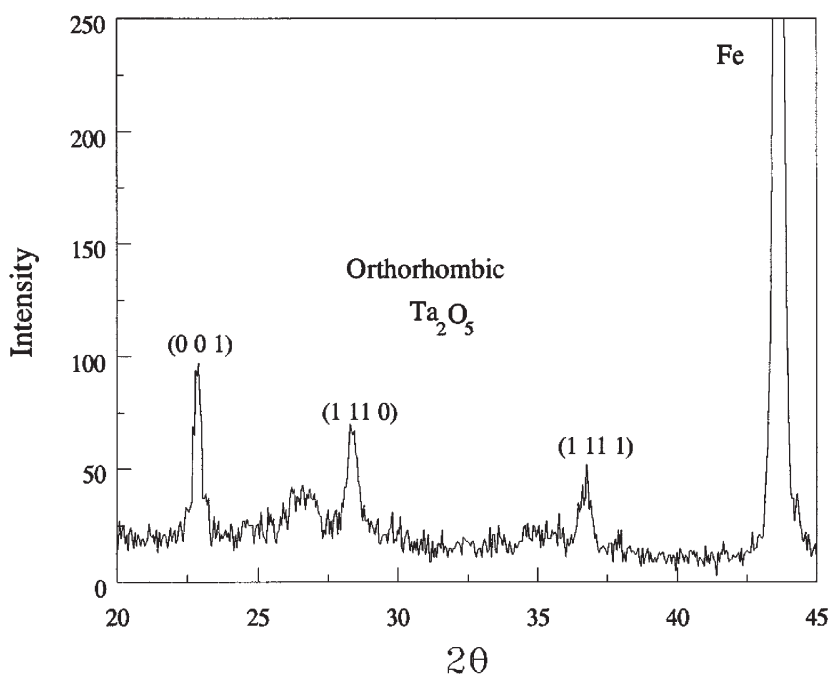

FIG. 4. XRD diagram of $\mathrm{Ta}_{2} \mathrm{O}_{5}$ film annealed at $800{ }^{\circ} \mathrm{C}$ for $60 \mathrm{~s}$.

the XRD spectrum of the film (Fig. 5) shows an additional diffraction peak at $2 \theta=26.5^{\circ}$ which corresponds to the (1100) plane of orthorhombic $\mathrm{Ta}_{2} \mathrm{O}_{5}$.

\section{Scanning electron microscopy (SEM) analysis}

The surface topography and integrity of the deposited $\mathrm{Ta}_{2} \mathrm{O}_{5}$ films were investigated with a scanning electron microscope. SEM investigations were also used to estimate the film thicknesses of the as-deposited $\mathrm{Ta}_{2} \mathrm{O}_{5}$ films. The SEM image in Fig. 6 shows the cross section of a stainless steel beam with the $\mathrm{Ta}_{2} \mathrm{O}_{5}$ film on it (narrow top white band).

The film thickness was estimated as $3 \mu \mathrm{m}$. The mean $\mathrm{Ta}_{2} \mathrm{O}_{5}$ sputter deposition rate on stainless steel, 


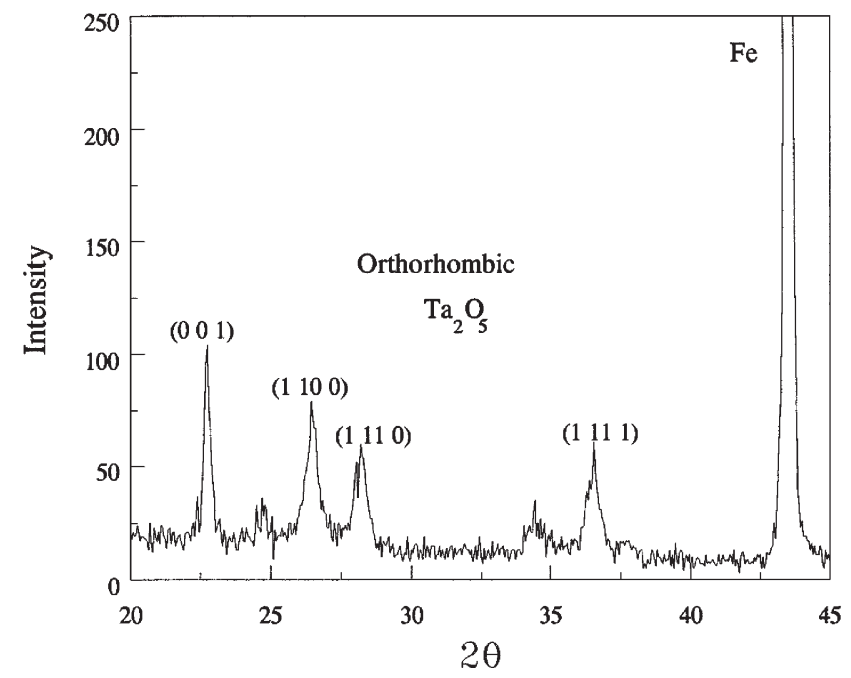

FIG. 5. XRD diagram of $\mathrm{Ta}_{2} \mathrm{O}_{5}$ film annealed at $900{ }^{\circ} \mathrm{C}$ for $60 \mathrm{~s}$.

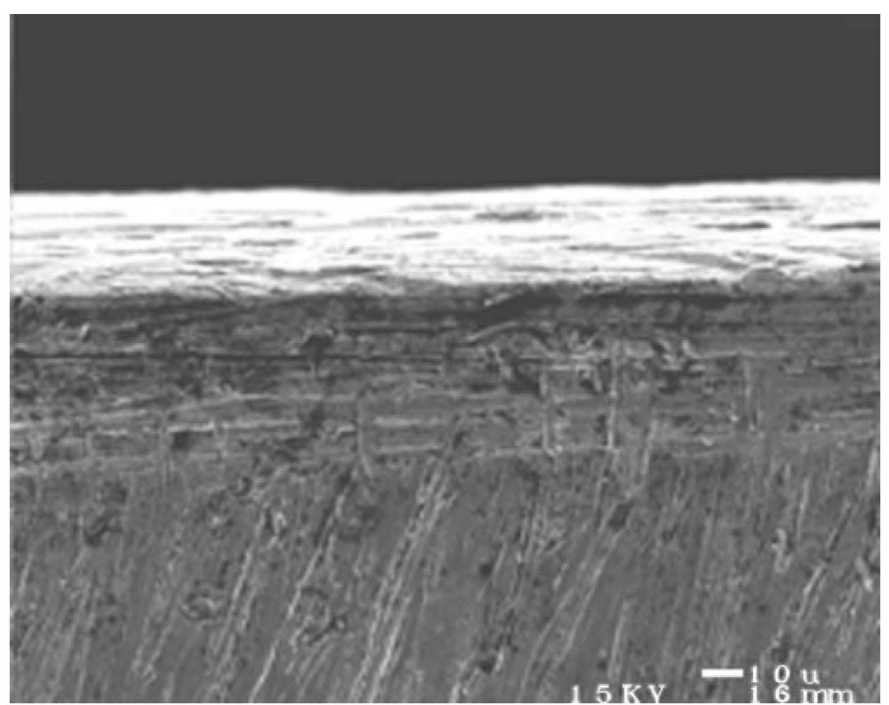

FIG. 6. SEM image of $\mathrm{Ta}_{2} \mathrm{O}_{5}$ film (narrow top white band) on a stainless steel substrate.

$R_{\mathrm{SS}, \mathrm{Ta}_{2} \mathrm{O}_{5}}$, was calculated by dividing the estimated film thickness, $d_{\mathrm{SS}, \mathrm{Ta}_{2} \mathrm{O}_{5}}$, by the deposition time, $t_{\mathrm{SS}, \mathrm{Ta}_{2} \mathrm{O}_{5}}$ :

$$
\begin{aligned}
R_{\mathrm{SS}, \mathrm{Ta}_{2} \mathrm{O}_{5}} & =\frac{d_{\mathrm{SS}, \mathrm{Ta}_{2} \mathrm{O}_{5}}}{t_{\mathrm{SS}, \mathrm{Ta}_{2} \mathrm{O}_{5}}} \\
& =\frac{3 \mu \mathrm{m}}{3 \mathrm{~h}} \\
& =1 \mu \mathrm{m} / \mathrm{h} .
\end{aligned}
$$

\section{EXPERIMENTAL EVALUATION OF THE SENSING ABILITY OF $\mathrm{Ta}_{2} \mathrm{O}_{5}$ FILMS}

\section{A. Cantilevered beam tests at room temperature}

A schematic of the experimental setup is shown in Fig. 7. A stainless steel beam was sputter coated on one

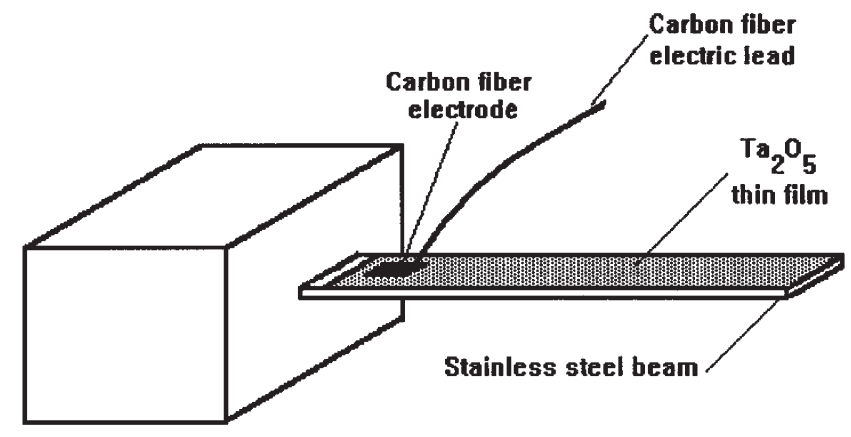

FIG. 7. Schematic of the experimental setup for cantilevered beam tests at room temperature.

side with a $\mathrm{Ta}_{2} \mathrm{O}_{5}$ thin film, and the unannealed and annealed films were tested for vibration sensing ability. The stainless steel beam served as one electrode and a carbon fiber electrode was glued on the top of the film to serve as the other electrode. These two electrodes were connected to a digital storage oscilloscope. The beam was clamped at one end and displaced at the free end to vibrate freely. The voltage signal from the $\mathrm{Ta}_{2} \mathrm{O}_{5}$ film was recorded on the oscilloscope. This signal was then transferred to a personal computer.

The voltage signal from the unannealed $\mathrm{Ta}_{2} \mathrm{O}_{5}$ film for an initial beam displacement of $4 \mathrm{~cm}$ is shown in Fig. 8. The signal exhibits a maximum magnitude of $2.5 \mathrm{mV}$ (peak to peak) and the primary natural vibration frequency (first vibration mode) of $300 \mathrm{~Hz}$ can be seen clearly.

The voltage signals from the $\mathrm{Ta}_{2} \mathrm{O}_{5}$ films annealed at 700,800 , and $900{ }^{\circ} \mathrm{C}$ are shown in Figs. 9, 10, and 11 , respectively, for an initial beam displacement of $4 \mathrm{~cm}$ for each beam. The signal responses of the

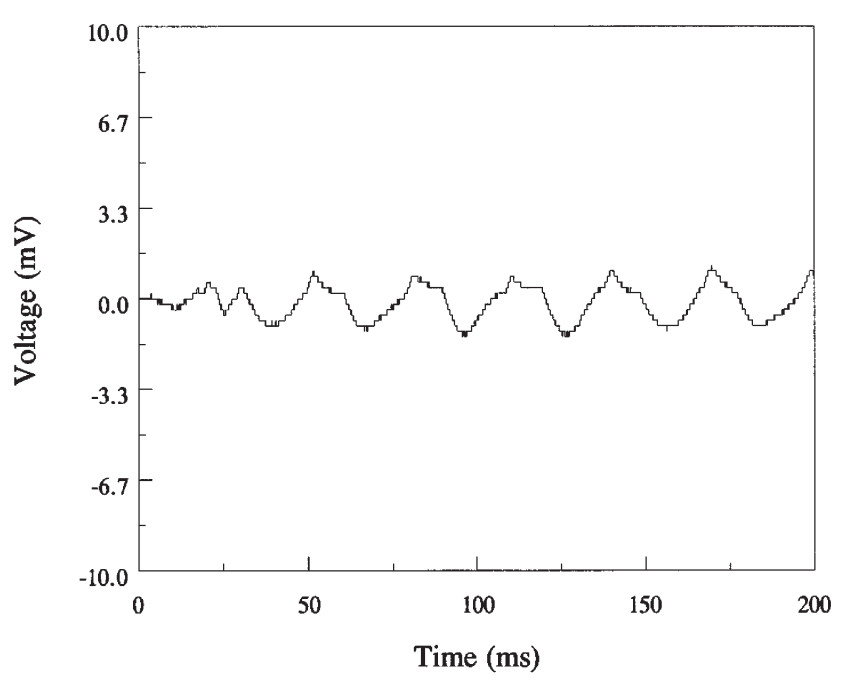

FIG. 8. Signal response of unannealed $\mathrm{Ta}_{2} \mathrm{O}_{5}$ film in the cantilevered beam test at room temperature. 


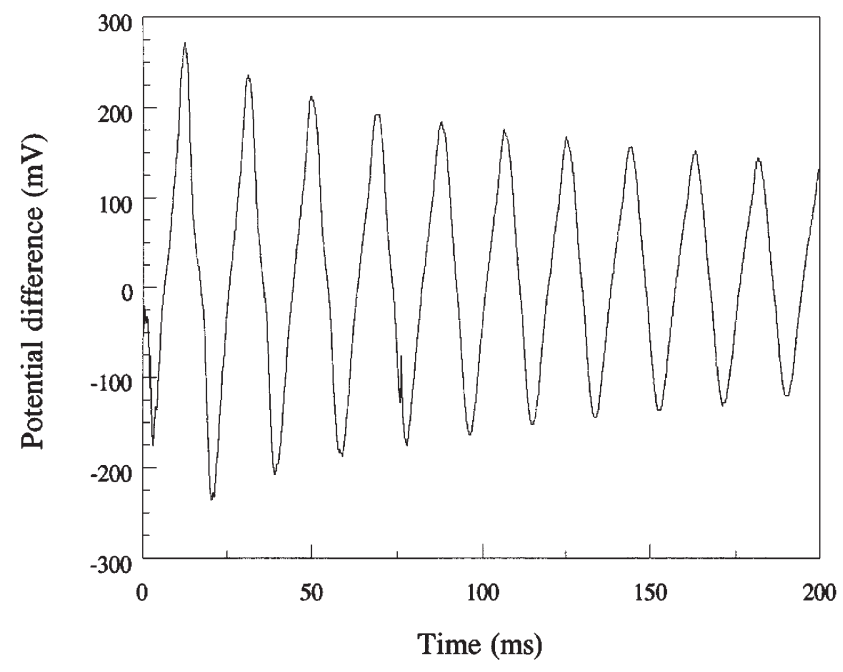

FIG. 9. Signal response of $\mathrm{Ta}_{2} \mathrm{O}_{5}$ film annealed at $700{ }^{\circ} \mathrm{C}$ for $60 \mathrm{~s}$ in the cantilevered beam test at room temperature.

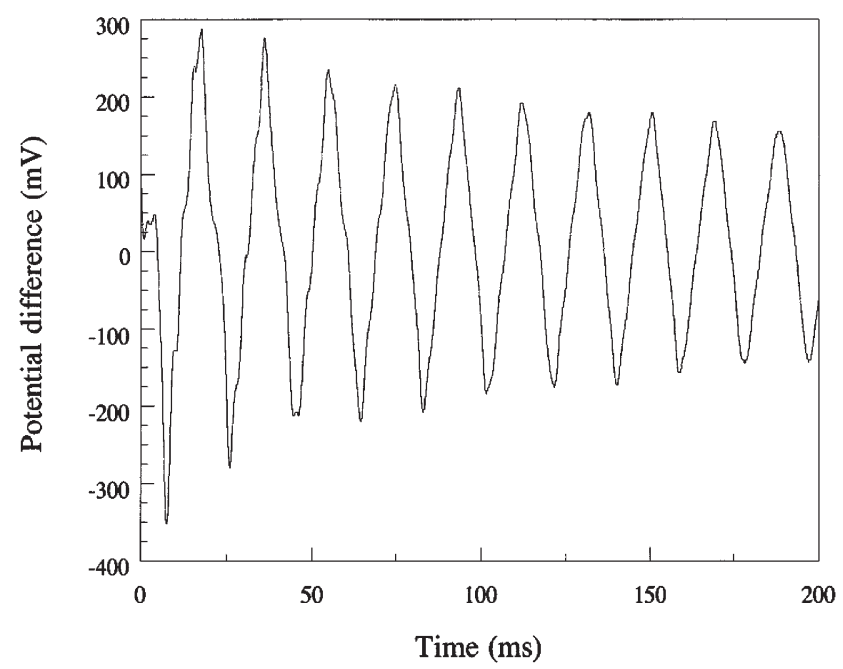

FIG. 10. Signal response of $\mathrm{Ta}_{2} \mathrm{O}_{5}$ film annealed at $800{ }^{\circ} \mathrm{C}$ for $60 \mathrm{~s}$ in the cantilevered beam test at room temperature.

annealed films are significantly stronger than that of the unannealed $\mathrm{Ta}_{2} \mathrm{O}_{5}$ film. A signal with a magnitude of about $500 \mathrm{mV}$ (peak to peak maximum) was detected in the film annealed at $700{ }^{\circ} \mathrm{C}$ (Fig. 9), $650 \mathrm{mV}$ (peak to peak maximum) for the film annealed at $800{ }^{\circ} \mathrm{C}$ (Fig. 10), and $200 \mathrm{mV}$ (peak to peak maximum) for the film annealed at $900{ }^{\circ} \mathrm{C}$ (Fig. 11). The primary natural vibration frequency was dominant in all the signals. From the signal response the primary vibration frequency of the beam was estimated to be $300 \mathrm{~Hz}$. Therefore, the annealed $\mathrm{Ta}_{2} \mathrm{O}_{5}$ film exhibits a low enough leakage current to measure vibration frequencies at $300 \mathrm{~Hz}$.

The signal strength of the $\mathrm{Ta}_{2} \mathrm{O}_{5}$ film is at its highest when the epoxy glue, which was used to glue

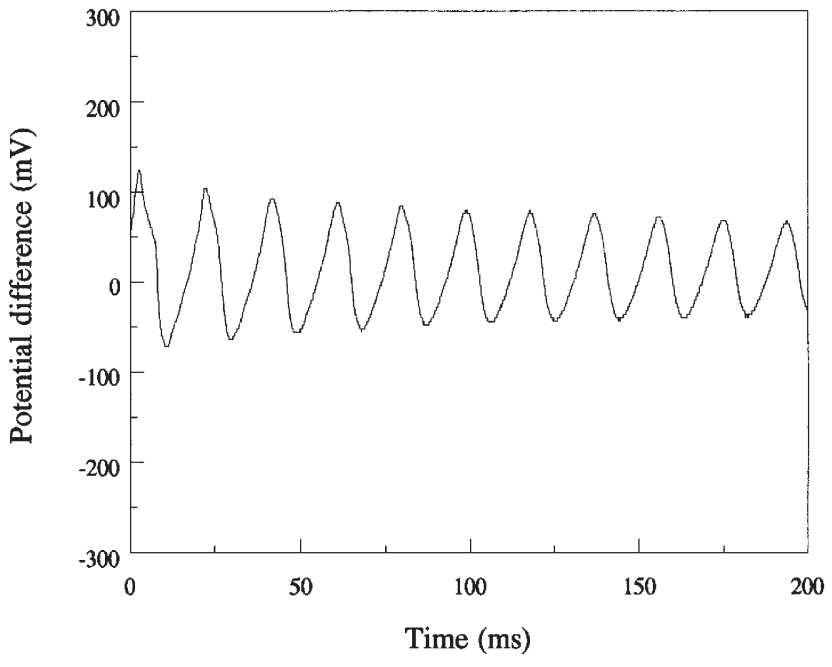

FIG. 11. Signal response of $\mathrm{Ta}_{2} \mathrm{O}_{5}$ film annealed at $900{ }^{\circ} \mathrm{C}$ for $60 \mathrm{~s}$ in the cantilevered beam test at room temperature.

the electrode onto the film, has cured properly (a few days). The signal strength from the films used in the initial displacement-test increased from about $10 \mathrm{mV}$ (peak to peak maximum), when tested on the same day the electrode was glued on, to signals in the order of 200 to $500 \mathrm{mV}$ when tested a few days after the electrode was glued on.

\section{B. Cantilevered beam tests at elevated temperatures}

The experimental setup for these tests is shown in Fig. 12. A beam was clamped at one end and inserted into a pipe with a $5 \mathrm{~cm}$ inner diameter. An electric air heater was used to blow air through the pipe. In the position directly above the free end of the beam, a pipe with a smaller diameter $(1.0 \mathrm{~cm})$ was fitted vertically, protruding slightly through the larger horizontal pipe.

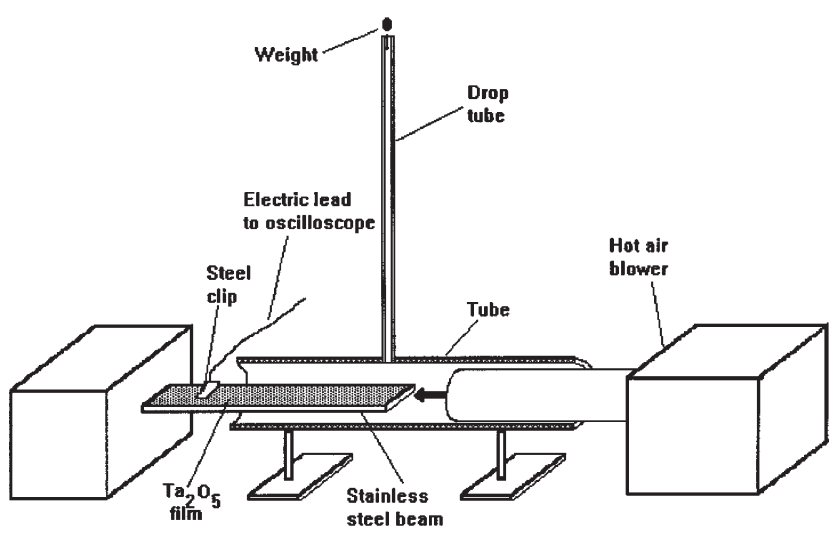

FIG. 12. Schematic of the experimental setup for high temperature cantilevered beam tests. 
This was used as a conduit to drop a weight onto the free end of the beam. A stainless steel electrode, shaped like an $\Omega$, was clipped over the film near the fixed end of the beam and insulated from the stainless steel substrate by a thin ceramic disk. The other electrode was the stainless steel beam itself. A fast response thermocouple ( $S$-type) was positioned on the film near the $\Omega$-shaped electrode.

A small copper weight was dropped onto the free end of the beam through the tube fitted on the pipe in such a way that the weight bounced off the beam after impact. This experiment was performed at different temperatures ranging from room temperature to $650{ }^{\circ} \mathrm{C}$. The $\mathrm{Ta}_{2} \mathrm{O}_{5}$ film was exposed to the maximum temperature for $90 \mathrm{~min}$. After the high temperature tests were completed, the experiment was repeated at room temperature to see what effect the exposure to high temperatures had on the sensing ability of the film. The films were also inspected visually for signs of cracking or spalling before and after exposure to the high temperatures.

The signal response of the $\mathrm{Ta}_{2} \mathrm{O}_{5}$ film at room temperature is shown in Fig. 13. The signal strength weakened as the temperature was raised [compare the signal response at $400{ }^{\circ} \mathrm{C}$ (Fig. 14) and at $650{ }^{\circ} \mathrm{C}$ (Fig. 15) with the signal at room temperature (Fig. 13)]. The signal was still measurable at $650{ }^{\circ} \mathrm{C}$ (which was the maximum temperature attainable with the heating equipment). During the high temperature tests it was noticed that the stainless steel beam softened at the higher temperatures.

The signal response at room temperature, after exposing the film to temperatures up to $650{ }^{\circ} \mathrm{C}$ for at least one and a half hours, was just as good or even better than the signal response before the high temperature tests (see Fig. 16). The weakening of the signal could

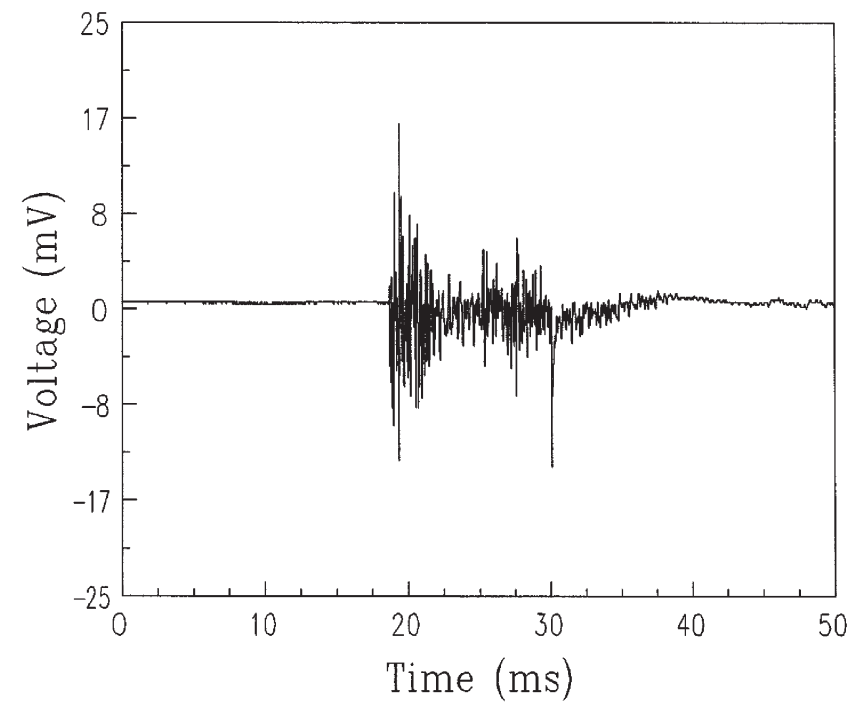

FIG. 13. Signal response of $\mathrm{Ta}_{2} \mathrm{O}_{5}$ film annealed at $700{ }^{\circ} \mathrm{C}$ for $60 \mathrm{~s}$ in the high temperature cantilevered beam test. $T=25^{\circ} \mathrm{C}$.

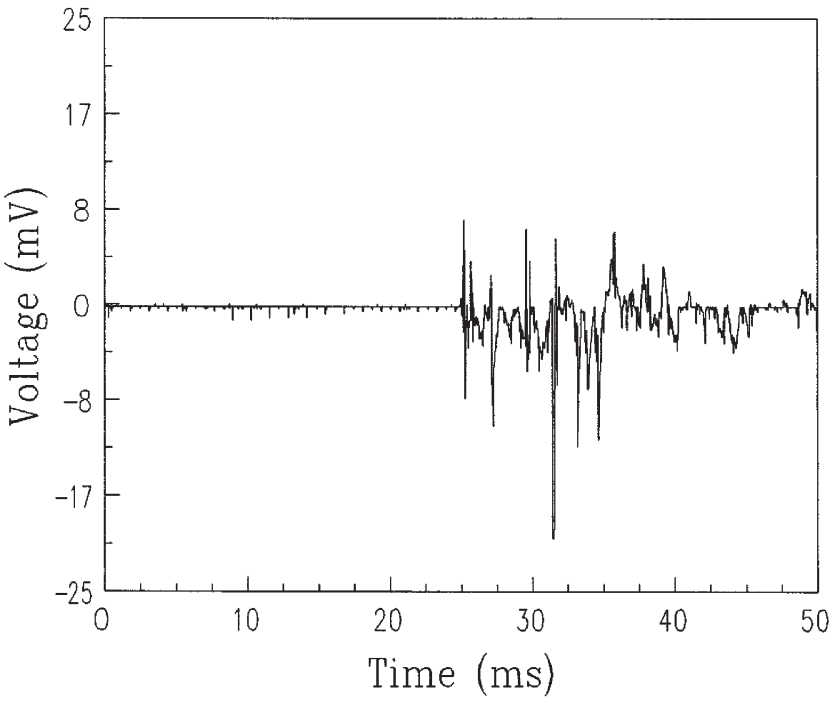

FIG. 14. Signal response of $\mathrm{Ta}_{2} \mathrm{O}_{5}$ film annealed at $700{ }^{\circ} \mathrm{C}$ for $60 \mathrm{~s}$ in the high temperature cantilevered beam test. $T=400{ }^{\circ} \mathrm{C}$.

therefore be related to the softening of the beam at higher temperatures which has changed the flexural rigidity, rather than the degradation of the vibration sensing ability of the film. The XRD spectrum of the film after completion of the high temperature tests shown increased crystallinity (see Fig. 17) as compared to the XRD spectrum before the high temperature tests (Fig. 3), and the (1100) diffraction peak is visible (Fig. 17). Inspection of films by optical microscope afterwards also showed no sign of cracking or spalling.

\section{DISCUSSION}

$\mathrm{X}$-ray amorphous $\mathrm{Ta}_{2} \mathrm{O}_{5}$ thin films, deposited with no intentional substrate heating by reactive dc magnetron sputtering, exhibit piezoelectric behavior in the form of vibration sensing (periodic film strain sensing). This phenomenon is probably due to microcrystallinity in the films.

The signal response of the annealed $\mathrm{Ta}_{2} \mathrm{O}_{5}$ films on the stainless steel beam in the initial displacement test was much stronger than the signal from the unannealed $\mathrm{Ta}_{2} \mathrm{O}_{5}$ film for similar test conditions. The annealing improved crystallization of the as-deposited, "amorphous" film, and greatly improved the piezoelectric activity of the $\mathrm{Ta}_{2} \mathrm{O}_{5}$ film.

The signal response of the $\mathrm{Ta}_{2} \mathrm{O}_{5}$ was measurable at a temperature of $650{ }^{\circ} \mathrm{C}$ in an air atmosphere, and no degradation of the film due to the exposures to these high temperatures were observed. The film was still in a very good condition after the high temperature tests and even produces a stronger signal response than before the experiments (compare Fig. 16 to Fig. 13). This could be due to annealing effects of the high 


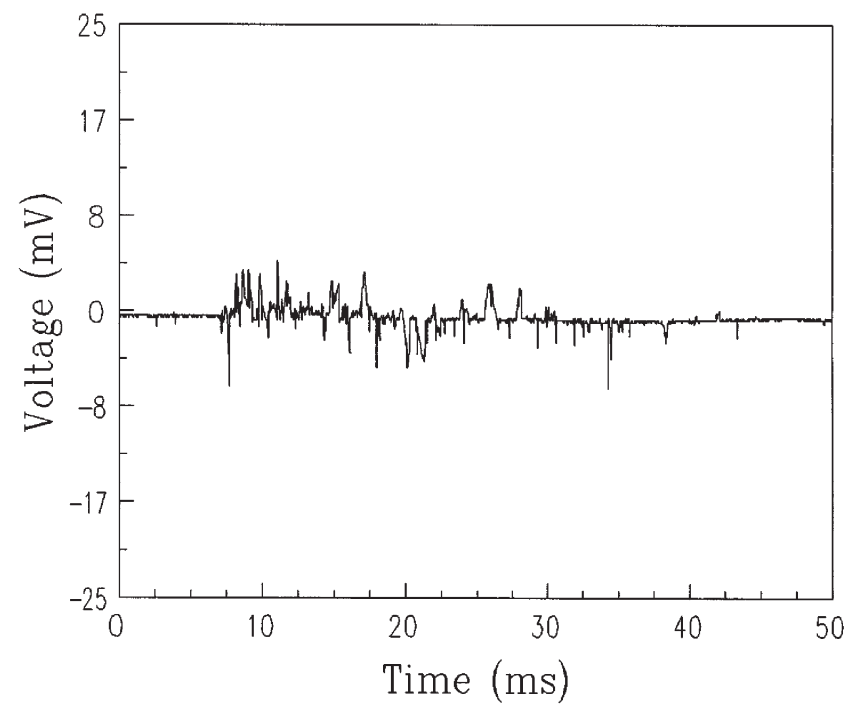

FIG. 15. Signal response of $\mathrm{Ta}_{2} \mathrm{O}_{5}$ film annealed at $700{ }^{\circ} \mathrm{C}$ for $60 \mathrm{~s}$ in the high temperature cantilevered beam test. $T=650{ }^{\circ} \mathrm{C}$.

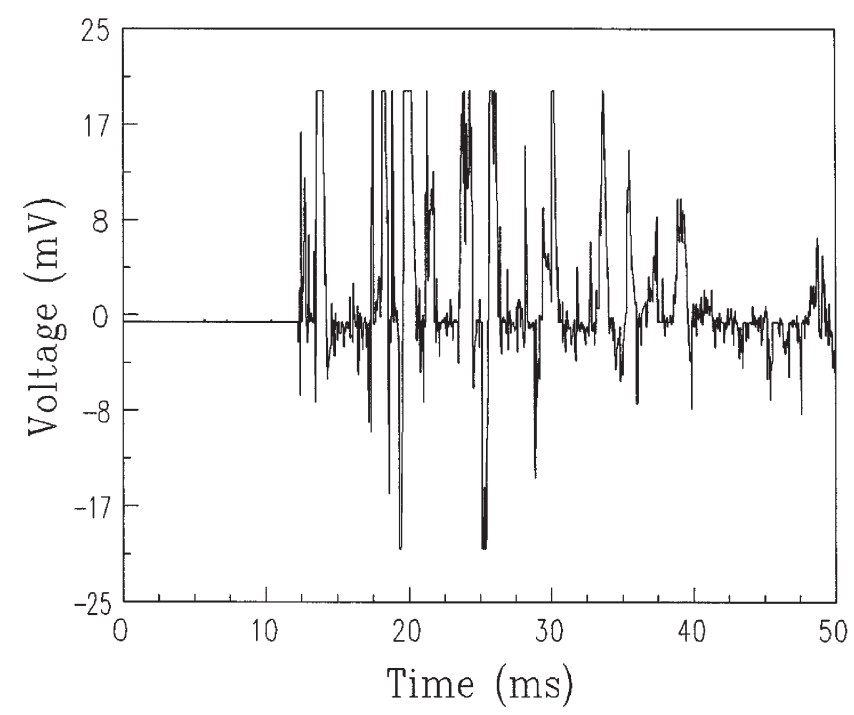

FIG. 16. Signal response of $\mathrm{Ta}_{2} \mathrm{O}_{5}$ film annealed at $700{ }^{\circ} \mathrm{C}$ for $60 \mathrm{~s}$ in the high temperature cantilevered beam test. $T=25^{\circ} \mathrm{C}$ (after high temperature exposure).

testing temperatures on the $\mathrm{Ta}_{2} \mathrm{O}_{5}$ film, leading to a more crystalline film. The nature of the high temperature test vibrations was different than that of the initial displacement vibration experiments because the perturbations were different. The drop test induced vibrations which were more intense, and the initial displacement corresponds more to the eigenfunction of the primary frequency. A larger contribution of higher frequencies can therefore be expected in the weight drop test than in the initial displacement and release test. Although no vibration frequency analysis was done on the signals

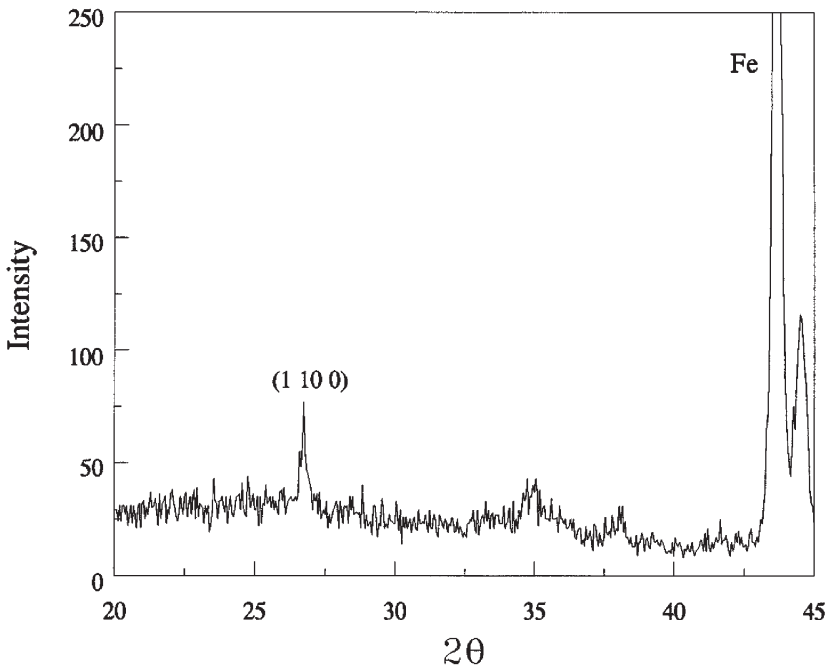

FIG. 17. XRD diagram of $\mathrm{Ta}_{2} \mathrm{O}_{5}$ film annealed at $700{ }^{\circ} \mathrm{C}$ for $60 \mathrm{~s}$ and then exposed to temperatures up to $650{ }^{\circ} \mathrm{C}$ for 90 min during the high temperature tests.

obtained from the high temperature experiments, the piezoelectric sensing ability of orthorhombic $\beta-\mathrm{Ta}_{2} \mathrm{O}_{5}$ at temperatures up to $650{ }^{\circ} \mathrm{C}$ was demonstrated. The piezoelectric sensing ability of orthorhombic $\beta-\mathrm{Ta}_{2} \mathrm{O}_{5}$ has not previously been reported and it could be used as a high temperature vibration sensing material.

In this study it was shown that reactively sputtered $\mathrm{Ta}_{2} \mathrm{O}_{5}$ thin films which are rapidly annealed at $700-900{ }^{\circ} \mathrm{C}$ can be used as piezoelectric sensing material to detect vibrations in structures at temperatures ranging from room temperature to $650{ }^{\circ} \mathrm{C}$ and over a wide range of vibration frequencies from $300 \mathrm{~Hz}$ and higher.

Only crystals of the 222 and $2 \mathrm{~mm}$ point groups in the orthorhombic crystal class can be piezoelectric. ${ }^{22}$ Therefore, the $\mathrm{Ta}_{2} \mathrm{O}_{5}$ crystals must belong to one of these point groups. SAW characteristics of the film can be used to determine the point group just as Nakagawa et al. ${ }^{23}$ did for the monoclinic form.

\section{REFERENCES}

1. H. Jehn and E. Olzi, J. Less Common Metals 27, 297 (1972).

2. N.C. Stephenson and R. S. Roth, J. Solid State Chem. 3, 145 (1970).

3. B.T. Boiko, V.R. Kopach, N.G. Krushedol'skaya, P.A. Panchekha, Y.L. Pozdeev, and V. V. Starikov, Izv. Vyssh. Uchebn. Zaved. Fiz. 1, 46 (1991).

4. L. B. Dubrovskaya, G. P. Shveikin, and P. V. Gel'd, Zh. Neorg. Khim. 9, 1182 (1964).

5. A. Raisman and F. Holzberg, in High Temperature Oxides II, edited A. M. Harper (Academic Press, New York, 1970).

6. Y. Nakagawa and Y. Gomi, Appl. Phys. Lett. 46, 139 (1985).

7. Y. Nakagawa and T. Okada, J. Appl. Phys. 68, 556 (1990).

8. M. Maeda, T. Hironari, and I. Satoshi, Jpn. J. Appl. Phys. 30 (9B), 2394 (1991). 
9. A. Schaefer, H. Shmitt, and A. Dorr, Ferroelectrics 69, 253 (1986).

10. K. Nagata and E. Harashima, Jpn. J. Appl. Phys. 9 B, 534 (1994).

11. M.S. Gadzhiev, I. V. Sandalyuk, and A.I. Trofimov, Izmeritel'naya Tekhnika 9, 1043 (1993).

12. Z. Weilie, Z. Peilin, and L. Sidong, Ferroelectrics 101, 173 (1990).

13. K. M. Rittenmeyer, J. Acoust. Soc. Am. 96, 307-318 (1994).

14. A. Song, E. S. Kim, and A. Kapila, J. Electron. Mater. 24 (2), 83 (1995).

15. J. M. Herbert, in Ferroelectric Transducers and Sensors (Gordon and Breach Science Publishers, Inc., New York, 1982), p. 397.

16. T. Ikeya and M. Senna, J. Non-Cryst. Solids 113, 51 (1989).

17. P. H. Chang and H. Y. Liu, Thin Solid Films 258, 56 (1995).
18. K. Shimizu, G. E. Thompson, and G.C. Wood, Philos. Mag. B 63, 891 (1991).

19. A. Pignolet, G. M. Rao, and S. B. Krupanidhi, Thin Solid Films 285, 230 (1995).

20. H. Shinriki, M. Nakata, Y. Nishioka, and K. Mukai, IEEE Electron Device Lett. 10, 514 (1989).

21. H. Treichel, A. Mitwalsky, N.P. Sandler, D. Tribula, W. Kern, and A.P. Lane, Adv. Mater. for Optics and Electronics 1, 299 (1992).

22. W. G. Cady, Piezoelectricity (McGraw-Hill, New York, 1946).

23. Y. Nakagawa, Y. Gomi, and T. Okada, J. Appl. Phys. 61, 5012 (1987). 